\title{
Assessment of interleukins 1 and 6 in hypertensive subjects
}

\author{
A.O. OLUBOYO*, C.M. OKORO, V.E. EKPO and B.O. OLUBOYO \\ Department of Medical Laboratory Science, College of Medicine and Health Sciences, Afe Babalola \\ University, Ado Ekiti, Ekiti State, Nigeria. \\ "Corresponding author; E-mail: oluboyoao@abuad.edu.ng; Tel: +2348062549343
}

\begin{abstract}
Hypertension has been the most frequent non-communicable disease and the most routinely diagnosed cardiovascular disorder in Nigeria. It has been linked to various diseases and complications. Therefore, the study assessed interleukin (IL) 1, 6 and anthropometric parameters in hypertensive subjects. A total of ninety subjects were investigated; thirty hypertensive subjects on antihypertensive therapy, thirty hypertensive subjects not on therapy and thirty control subjects without hypertension. Blood pressure was measured using sphygmomanometer (Omros, Japan) while body mass index (BMI) was determined by using the formula: weight/height $\left(\mathrm{kg} / \mathrm{m}^{2}\right)$. Interleukin 1 and 6 were determined using enzyme linked immunosorbent assay (ELISA) technique. The systolic blood pressure, diastolic blood pressure, IL-1 was significantly higher $(\mathrm{P}<0.05)$ in hypertensive subjects on antihypertensive agents and those not on antihypertensive agents compared with the control. There was no significant correlation between IL-1, IL-6 and anthropometric parameters $(\mathrm{P}>0.05)$ but IL-1 was significantly increased in females compared with male subjects. The study concluded that IL-1 and IL-6 are increased during hypertension. Thus, the parameters may be used in the assessment and monitoring of cases of hypertension so as to prevent development of inflammatory conditions in hypertensive subjects.
\end{abstract}

(C) 2019 International Formulae Group. All rights reserved.

Key words: IL-1, IL-6, blood pressure, BMI, hypertension.

\section{INTRODUCTION}

Hypertension (HTN) is a global problem which affects about $40 \%$ of the world's population and has been estimated to be the cause of a large part of death from cardiovascular diseases (Chamarthi et al., 2011; Howard et al., 2014).Worldwide hypertension is estimated to cause 7.5 million deaths and about $12.8 \%$ of the total deaths (Lim et al., 2012). In 2010 hypertension was believed to have been a factor in $18 \%$ of all deaths (9.4 million globally) (Campbell et al., 2015).
Hypertension and its complications form a large percentage of urgent medical admissions in urban hospitals in Nigeria (Akinlua et al., 2015; Ajayi et al, 2016). Hypertension is the most paramount modifiable risk factor for cardiovascular disease (Novo et al., 2009). The causes of hypertension are multifactorial and cut across every social class (Ghogomu et al., 2016; Norbert et al., 2017). Hypertension is linked with various diseases such as cardiovascular disease, hyperuricidemia, carbohydrate intolerance, renal failure and many more 
(Yeldu et al., 2018). It usually occurs as a result of environmental and genetic factors or an interaction between both factors (Poulter et al., 2015). Risk factors of primary hypertension include excessive intake of dietary salt, overweight, smoking, and alcohol use (Ma et al., 2015; Poulter et al., 2015; CDC, 2019).

In the immune system, the production of IL-1 is in most cases induced, generally resulting in inflammation. IL-1 is extremely produced by tissue macrophages, monocytes, fibroblasts, and dendritic cells, but is also exhibited by B lymphocytes, natural killer (NK) cells, microglia, and epithelial cells (Duque and Descoteaux, 2014; Yan et al., 2019). They form a major part of the inflammatory response of the body against infection. Interleukin 6 (IL-6) is a pleiotropic cytokine with a broad range of biologic activities in control of immunological process, production of blood cells, inflammation, and formation of cancerous cells (Tanase et al., 2019). IL-1 also induces its own production and processing which is key in the pathogenesis of many auto inflammatory diseases (Dinarello, 2012; Doria et al., 2012). Inflammatory mediators play key roles in atherosclerosis, from initial leukocyte recruitment through rupture of the atherosclerotic plaque (Petrella, 2010). Inflammation is also an early event in cardiac stress as elevated levels of endothelial adhesion molecules and increased inflammatory cytokine and chemokine production or release are observed in affected cardiac tissues (Glezeva et al., 2014). Interleukin-6 is a classic pro-inflammatory cytokine needed to mount an effective immune response. It seems that interleukin-6 has an important role in the dynamic and superbly orchestrated process of innate immunity after myocardial infarction. Interleukin-6 timely suppresses innate immune signals to prevent the catastrophic consequences of uncontrolled inflammation on cardiac geometry and function, and thus tunes myocardial remodeling (Huang et al., 2015). Therefore, the study assessed interleukin 1 and 6 in hypertensive subjects to determine whether there are alterations in the levels of these inflammatory cytokines since there is involvement of inflammatory processes in hypertensive subjects.

\section{MATERIALS AND METHODS}

This research was conducted in Federal Teaching Hospital, Ido-Ekiti, Ekiti State, Nigeria. All sample analysis was carried out in the laboratory of the Medical Laboratory Science Department, Afe Babalola University. Ethical approval was sought for and obtained from Federal Teaching Hospital, Ido-Ekiti, Ekiti State. The nature and purpose of research was explained to each participant using an informed consent form for literate participants and verbal explanation for illiterate participants. Participants were not forced to answer questions but at their free will. The participants were ensured of confidentiality and voluntary participation but were told that there is no financial benefit whatsoever. This study included ninety subjects; sixty hypertensive subjects out of whom thirty subjects were on antihypertensive therapy and thirty apparently healthy subjects without hypertension (control subjects). The study did not involve subjects below 18 years, pregnant women, nursing mothers, diabetes mellitus subject and other disease conditions.

Weight and height of subjects were measured using a bathroom scale and a height gauge (Pasco scale co., Ltd, India). Body mass index (BMI) was determined by using the formula: weight/height $\left(\mathrm{kg} / \mathrm{m}^{2}\right)$. Blood pressure was taken from the non-dominant arm using appropriate cuff size and mercury sphygmomanometer (Omros, Japan). Systolic blood pressure (SBP) and diastolic blood pressure (DBP) were the first and fifth koroktoff sounds respectively. Venous blood sample of about five milliliters $(5 \mathrm{ml})$ was collected from the subjects for the analysis of interleukin 1 and 6 using ELISA technique purchased from Melsin Medical Co., Limited, China. 


\section{Statistical Analysis}

The data obtained were subjected to statistical analysis using Statistical Package for Social Sciences version 23 (version 23.0 software, SPSS Inc. Chicago, Illinois, USA). All parameters were expressed as mean \pm standard deviation (SD). Student ' $t$ ' test was the tool of choice and values were found to be statistically significant at $\mathrm{p}<0.01$ or $\mathrm{p}<0.05$.

\section{RESULTS}

Table 1 shows the mean \pm SD of BMI, blood pressure, IL-1 and IL-6 in hypertensive subjects on antihypertensive agent, those not on antihypertensive agents and control. The systolic blood pressure, diastolic blood pressure, IL-1 were significantly higher $(\mathrm{P}<0.05)$ in hypertensive subjects on antihypertensive agents and those not on antihypertensive agents compared with the control group. IL-6 was significantly lower in hypertensive subjects on antihypertensive agent but high in those not on antihypertensive agents compared with control. The BMI was not significantly higher in hypertensive subjects compared with the control group.

Table 2 shows the relationship between the parameters in hypertensive subjects. It shows that there was positive significant correlation between systolic and diastolic blood pressure at $\mathrm{p}<0.05$ but there was no significant correlation between IL-1, IL-6 and anthropometric parameters.

Figure 1 shows anthropometric parameters, IL-1 and Il-6 in hypertensive subjects according to gender. Systolic BP was significantly higher in males compared with females whereas IL-1 was significantly increased in females compared with male subjects.

Table 1: Anthropometric parameters, interleukin 1 and 6 in hypertensive and control subjects.

\begin{tabular}{|c|c|c|c|c|c|}
\hline \multirow[t]{2}{*}{ Parameters } & \multirow{2}{*}{$\begin{array}{l}\text { Hypertensives } \\
\text { on treatment } \\
\mathrm{N}=30\end{array}$} & \multirow{2}{*}{$\begin{array}{l}\text { Hypertensives } \\
\text { not on } \\
\text { treatment } \mathrm{N}=\mathbf{3 0}\end{array}$} & \multirow{2}{*}{$\begin{array}{l}\text { Control } \\
\mathrm{N}=30\end{array}$} & \multirow[t]{2}{*}{ F-values } & \multirow[t]{2}{*}{ P-values } \\
\hline & & & & & \\
\hline BMI $\left(\mathrm{Kg} / \mathrm{m}^{2}\right)$ & $29.44 \pm 5.65$ & $28.14 \pm 4.29$ & $27.38 \pm 4.86$ & 1.382 & 0.257 \\
\hline $\begin{array}{l}\text { Systolic } \\
(\mathrm{mmHg})\end{array}$ & $145.93 \pm 15.81$ & $152.10 \pm 12.84$ & $107.73 \pm 10.40$ & 99.362 & $0.000 * *$ \\
\hline $\begin{array}{ll}\text { Diastolic } & \text { Bp } \\
(\mathrm{mmHg}) & \end{array}$ & $86.87 \pm 15.79$ & $93.73 \pm 10.97$ & $68.83 \pm 8.80$ & 33.258 & $0.000 * *$ \\
\hline IL-1 (Pg/mL) & $17.65 \pm 12.57$ & $20.65 \pm 4.65$ & $12.16 \pm 2.76$ & 8.925 & $0.000 * *$ \\
\hline IL-6 (Pg/mL) & $8.84 \pm 1.86$ & $15.96 \pm 10.60$ & $10.00 \pm 5.65$ & 8.897 & $0.000 * *$ \\
\hline $\begin{array}{l}\text { Where } \\
\text { ** Significant levels } \\
\text { BMI = body mass ind } \\
\mathrm{Bp}=\text { Blood pressure } \\
\mathrm{Kg} / \mathrm{m}^{2}=\text { Kilogram } / \mathrm{m} \\
\mathrm{mmHg}=\text { millimetre } \\
\mathrm{Pg} / \mathrm{mL}=\text { picogram } / \mathrm{n}\end{array}$ & $\begin{array}{l}\mathrm{P}<0.05 \\
\mathrm{X} \\
\text { eter }^{2} \\
\text { mercury } \\
\text { illiliter. }\end{array}$ & & & & \\
\hline
\end{tabular}


Table 2: Correlation of Interleukin 1 and 6 with other parameters in hypertensive Subjects.

\begin{tabular}{ccccccc}
\hline Parameters & $\begin{array}{c}\text { Correlations } \\
(\mathbf{R}) / \text { P values }\end{array}$ & $\begin{array}{c}\text { Systolic } \\
\text { Bp }\end{array}$ & $\begin{array}{c}\text { Diastolic } \\
\text { Bp }\end{array}$ & BMI & IL-1 & IL-6 \\
\hline Systolic Bp & $\mathrm{R}$ & 1.000 & $0.326^{*}$ & -0.049 & -0.075 & -0.007 \\
& $\mathrm{P}$ & - & 0.011 & 0.707 & 0.570 & 0.956 \\
Diastolic Bp & $\mathrm{R}$ & $0.326^{*}$ & 1.000 & -0.097 & 0.052 & 0.042 \\
& $\mathrm{P}$ & 0.011 & - & 0.463 & 0.691 & 0.752 \\
& $\mathrm{R}$ & -0.049 & -0.097 & 1.000 & -0.097 & -0.140 \\
BMI & $\mathrm{P}$ & 0.707 & 0.463 & - & 0.461 & 0.287 \\
& $\mathrm{R}$ & -0.075 & 0.052 & -0.097 & 1.000 & 0.080 \\
$\mathrm{IL}-1$ & $\mathrm{P}$ & 0.570 & 0.691 & 0.461 & - & 0.542 \\
& $\mathrm{R}$ & -0.007 & 0.042 & -0.140 & 0.080 & 1.000 \\
\hline
\end{tabular}

* significant levels at $\mathrm{P}<0.05$.

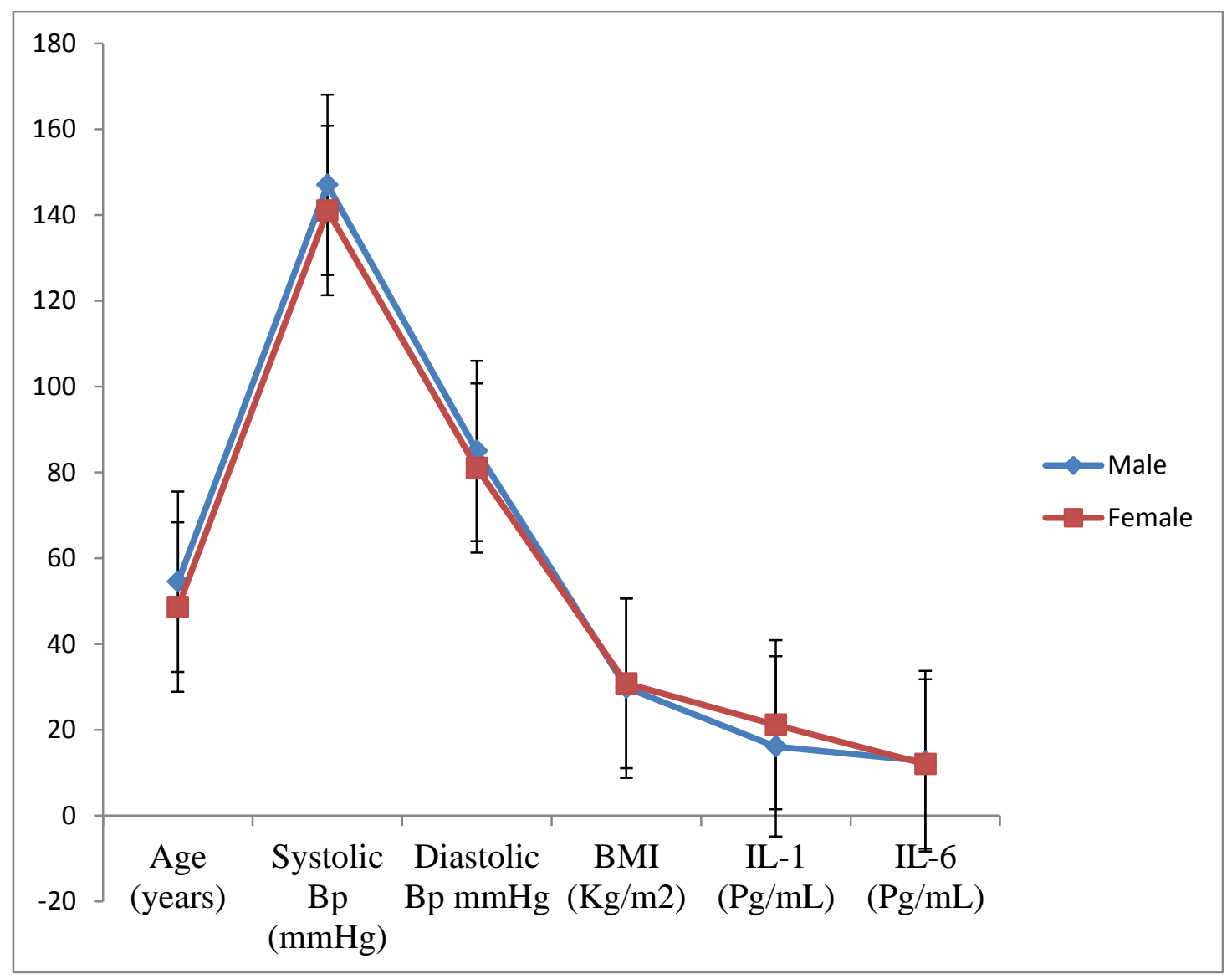

Figure 1: Anthropometric parameters, IL-1 and IL-6 in hypertensive subjects according to gender. 


\section{DISCUSSION}

In this study, systolic and diastolic blood pressures of hypertensive subjects were assessed and compared between the hypertensive subjects and control (Table 1). The systolic and diastolic blood pressures were found to be significantly higher in hypertensive subjects compared with control. This research agrees with the works of Oluboyo et al. (2018); Odewusi and Osadolor (2019) where systolic and diastolic blood pressures were seen to be significantly higher in hypertensive subjects compared with control. There was also a significant increase in systolic blood pressure of the males when compared with the female subjects.

Body mass index (BMI) was also assessed and compared between the hypertensive subjects compared with control in this study. The BMI of hypertensive subjects on therapy and those not on therapies were higher but not statistically significant when compared with control subjects. This supports the works of Zhang et al. (2016) and Norbert et al. (2017) where increased BMI has been associated with hypertension. This research also agrees with the work of Yeldu et al. (2018) where body composition variables such as weight, skin fold thickness and others have been shown to be significantly correlated with blood pressure in adults.

In this study, IL-1 was significantly higher in hypertensive subjects compared with control. This probably may be as a result of its role as a powerful inducer of the innate immune response (Dinarello et al., 2012). IL-1 is considered to be an "early-response" cytokine, involved in energy homeostasis and inflammation, connected to metabolism mechanisms (Erion et al., 2014). There was also a significant increase in IL-6 of hypertensive subjects not on therapy compared with those on therapy and control subjects. IL-6 has been shown to be a proinflammatory cytokine produced by various cells including macrophages, endothelial cells and vascular smooth muscle cells. It is an early regulator of inflammation, which plays a critical role in driving the chronic inflammatory process (Barnes et al., 2011; Mao et al., 2017). IL-6 is the major proinflammatory cytokine and has been described to be linked with hypertension and atherosclerosis (Tanase et al., 2019). This finding agrees with the reports of GibasDorna et al. (2015) where individuals with hypertension were reported to have higher levels of IL-6 compared with control subjects. There was no significant correlation between IL- 1, IL- 6 and other parameters in the hypertensive subjects (Table 2). The findings of significant increase in IL- 1 and IL- 6 show that there is involvement of inflammatory processes and immune response in hypertensive subjects. Although, the use of anti- hypertensive agents may regulate the inflammatory process since low level of IL- 6 was observed in hypertensive subjects on therapy.

This study also found that a higher number of hypertensive subjects were females. This finding is in agreement with the report of Everett and Zajacova (2015) where it was reported that the rate of hypertension is higher in females than males (Figure 1). However, systolic blood pressure was found to be significantly higher in men compared with women while BMI was higher in females but not significant. This observation is in line with the findings of Akili et al. (2014) where females were found to have a higher body mass index than males. There was significant increase in IL-1 of female hypertensive subjects compared with male hypertensives while there was no significant increase in IL-6 of the male subjects compared with female hypertensive subjects. This partly supports the findings of Gibas-Dorna et al. (2015) which shows that IL-6 is raised in men. There was no significant correlation when IL-1 and IL-6 were compared with other parameters in the hypertensive subjects. 


\section{Conclusion}

This study concluded that IL-1 and IL6 were increased in hypertensive subjects, although there was no significant correlation between IL-1 and IL-6 compared with other parameters. Thus, IL-1 and IL-6 may be used in the assessment and monitoring of cases of hypertension so as to prevent development of inflammatory conditions in hypertensive subjects.

\section{COMPETING INTERESTS}

The authors declare that there is no competing interest.

\section{AUTHORS' CONTRIBUTIONS}

$\mathrm{AOO}$ and $\mathrm{BOO}$ were responsible for the project design, survey, statistical calculations, writing and editing of the manuscript. CMO and VEE were responsible for experimental analysis, scientific and conceptual contributions to the manuscript.

\section{ACKNOWLEDGEMENTS}

The Authors acknowledge the support of the staff members of Chemical Pathology Laboratory of Federal Medical Center, Ido Ekiti, Ekiti State for their support during sample collection.

\section{REFERENCES}

Ajayi IO, Sowemimo IO, Akpa OM, Ossai NE. 2016. Prevalence of hypertension and associated factors among residents of Ibadan-North Local Government Area of Nigeria. Nig. J. Cardiol., 13: 67-75. DOI: 10.4103/0189-7969.165168

Akili H, Kayak M, Bekci TT. 2014. Genderrelated changes of the epicardial fat thickness and leptin in obstructive sleep apnea. Echocardiography, 31(4): 411-419. DOI: 10.1111/echo.12392

Akinlua JT, Meakin R, Umar AM, Freemantle N. 2015. Current prevalence pattern of hypertension in Nigeria: A systematic review. PLoS One, 10(10): e0140021. DOI: 10.1371/journal.pone. 0140021

Barnes TC, Anderson MA, Moots RJ. 2011. The many faces of 6nterleukin-6: The role of IL-6 in inflammation, vasculopathy, and fibrosis in systemic sclerosis. International Journal of Rheumatology, ID721608: 6p. DOI: http://dx.doi.org/10.1155/2011/721608

Campbell NR, Lackland DT, Lisheng L, Niebylski ML, Nilsson PM, Zhang XH. 2015. Using the global burden of disease study to assist development of nationspecific fact sheets to promote prevention and control of hypertension and reduction in dietary salt: a resource from the World Hypertension League. Journal of clinical hypertension, 17(3): 165-167. DOI: $10.1111 /$ jch. 12479

Center for Disease Control (CDC). 2019. High blood pressure fact sheet. CDC. www.cdc.gov/bloodpressure/about.htm Retrieved 6th March 2019.

Chamarthi B, Williams GH, Ricchiuti V, Srikumar N, Hopkins PN, Luther JM, Xavier JX, Thomas A. 2011. Inflammation and hypertension: The interplay of interleukin-6, dietary sodium and the renin-angiotensin system in humans. Am. J. Hypertens., 24(10): DOI: $10.1038 /$ ajh.2011.113

Dinarello CA, Simon A, van der Meer JW. 2012. Treating inflammation by blocking interleukin- 1 in a broad spectrum of diseases. Nat. Rev. Drug Discov., 11: 633-652. DOI: 10.1038/nrd3800

Doria A, Zen M, Bettio S, Gatto M, Bassi N, Nalotto L, Ghirardello A, Iaccarino L, Punzi L. 2012. Auto inflammation and autoimmunity: bridging the divide. Autoimmun Rev., 12: 22-30. DOI: 10.1016/j.autrev.2012.07.018

Duque GA, Descoteaux A. 2014. Macrophage Cytokines: Involvement in Immunity and Infectious Diseases. Front Immunol., 5: 491. DOI: 10.3389/fimmu.2014.00491 
Erion JR, Wosiski-Kuhn M, Dey A. 2014. Obesity elicits interleukin 1-mediated deficits in hippocampal synaptic plasticity. The Journal of Neuroscience, 34(7): 2618-2631. DOI: org/10.1523/jneurosci.4200-13.2014

Everett B, Zajacova A. 2015. Gender differences in hypertension and hypertension awareness among young adults. Biodemography Soc. Biol., 61(1): $1-17$.

DOI:

10.1080/19485565.2014.929488

Ghogomu SM, Tamutan MN, Musong JIM. 2016. Insertion/deletion gene variants of angiotensin converting enzyme do not predispose Cameroonians of the Bantu ethnic group to essential hypertension. Int. J. Biol. Chem. Sci., 10(4): 14841492.

DOI:

http://dx.doi.org/10.4314/ijbcs.v10i4.2

Gibas-Dorna M, Nowaki D, Piatek J. 2015.

Plasma gherilin and interleukin-6 levels correlate with body mass index and arterial blood pressure in males with essential hypertension. Journal of Physiology and Pharmacology, 66(3): 367-372.

Glezeva N, Baugh JA. 2014. Role of inflammation in the pathogenesis of heart failure with preserved ejection fraction and its potential as a therapeutic target. Heart Failure Review, 19(5):681694. DOI: $10.1007 / \mathrm{s} 10741-013-9405-8$

Howard A, Bauchner A, Phil BA, Fontanarosa A, Robert MA, Golub A. 2014. Updated guidelines for management of high blood pressure: recommendations, review, and responsibility. JAMA., 311(5):477-478. DOI:10.1001/jama.2013.284432

Huang M, Yang D, Xiang M, Wang J. 2015. Role of interleukin- 6 in regulation of immune responses to remodeling after myocardial infarction. Heart Failure Review, 20(1): 25-38.

DOI: $10.1007 / \mathrm{s} 10741-014-9431-1$
Lim SS, Vos T, Flaxman AD, Daniel SK, Adair-Rohani H. 2012. A comparative risk assessment of burden of disease and injury attributable to 67 risk factors and risk factor clusters in 21 regions, 19902010: a systematic analysis for the global burden of disease study 2010. Lancet, 380: $2224-2260$. DOI: $10.1016 / \mathrm{S} 0140-$ 6736(12)61766-8

Ma Y, He FJ, MacGregor GA. 2015. High salt intake: independent risk factor for obesity? Hypertension, 66(4):843-849. DOI:

10.1161/Hypertensionaha.115.05948

Mao SQ, Sun JH, Gu TL, Zhu FB, Yin FY, Zhang LN. 2017. Hypomethylation of interleukin-6 (IL-6) gene increases the risk of essential hypertension: a matched case-control study. Journal of Human Hypertension, 31(8): 530-536. DOI: 10.1038/jhh.2017.7

Norbert U, Romokere A, Odia J. 2017. Prevalence and determinants of left ventricular geometric and functional abnormalities in asymptomatic hypertensive adults at a tertiary hospital, South- Southern Nigeria. International Journal of Internal Medicine, 6(1): 1626. DOI:10.5923/j.ijim.20170601.03

Novo S, Lunetta M, Evola S, Novo G. 2009. Role of ARBs in the blood hypertension therapy and prevention of cardiovascular events. Current Drug Targets, 10(1): 20-25. DOI: $10.2174 / 138945009787122897$

Odewusi OO, Osadolor HB. 2019. Interleukin 10 And 18 Levels in Essential Hypertensive. J. Appl. Sci. Environ. Manage, 23(5): 819-824. DOI: https://dx.doi.org/10.4314/jasem.v23i5.7.

Oluboyo AO, Zaruq AO, Oluboyo BO, Onyeaghala AA, Olayanju AJ. 2018. Assessment of serum interleukin-18 and some markers of hypertension. British Journal of bio-medical research, 2(4): 
420-425.

DOI:

https://doi.org/10.24942/bjbmr.2018.281

Petrella RJ. 2010. The impact of angiotensin-II receptor blockers on cardiovascular events in hypertensive patients - evidence from real-life databases. European Cardiology, 6(3): 33-38.

DOI: http://dx.doi.org/10.15420/ecr.2010.6.3 .33 .

Poulter NR, Prabhakaran D, Caulfield M. 2015. Hypertension. Lancet, 386(9995): 801-812.

Tanase DM, Gosav EM, Radu S, Ouatu A, Rezus C, Ciocoiu M, Costea CF, Floria M. 2019. Arterial hypertension and interleukins: potential therapeutic target or future diagnostic marker?

International Journal of Hypertension, ID3159283:

$17 \mathrm{p}$.

DOI: https://doi.org/10.1155/2019/315928
Yan X, Xie B, Wu G, Hu J, Wang D, Cai X, Li J. 2019. Interleukin-37: The effect of anti-inflammatory response in human coronary artery endothelial cells. Mediators of Inflammation, ID2650590: 12p.

DOI: https://doi.org/10.1155/2019/2650590

Yeldu MH, Yale BM, Akuyam SA, Isezuo SA. 2018. Inflammatory biomarkers and their correlates among hypertensive population in two tertiary hospitals in Sokoto, Nigeria. Int. J. Biol. Chem. Sci., 12(3): 1131-1140. DOI: https://dx.doi.org/10.4314/ijbcs.v12i3.5

Zhang J, Rudemiller NP, Wu M, McDonough AA, Crowley SD. 2016. Interleukin-1 receptor activation potentiates salt reabsorption in angiotensin II induced hypertension via NHCC2 cotransporter in the nephron. Cell Metabolism, 23(2): 360-368. DOI: 10.1016/j.cmet.2015.11.013 